\title{
As Vozes pelo Caminho do Mover: Som, cinestesia e o si mesmo como pro- cesso na somática do sistema Laban/Bartenieff
}

\author{
Daniel Magalhães de Andrade Lima \\ Universidade Federal de Pernambuco - UFPE, Recife/PB, Brasil \\ E-mail: danmalima@gmail.com / daniel.andradelima@ufpe.br
}

\section{Resumo}

O artigo se dedica a mapear, cruzar e agrupar saberes que abordam voz por uma perspectiva dos estudos do movimento desenvolvidos pelo Sistema Laban/Bartenieff. A pesquisa gira em torno, portanto, da construção de fundamentos para o trabalho vocal por parâmetros do mover. Durante tal processo, discussões ligadas aos desdobramentos propostos por autoras como Regina Miranda, Barbara Adrian e Bonnie Bainbridge Cohen são desenvolvidas. Frisa-se, assim, maneiras plurais de entender a voz como movimento, como perturbação espacial e como agente do mover. Por fim, se pontua a importância de um trabalho vocal na abertura de possibilidades de estar no mundo, reconhecendo a dinâmica entre escuta e produção vocal como uma que enfatiza os nossos processos de autoatualização.
The article is dedicated to map, cross and group knowledges that addresses voice from a perspective of the Laban/Bartenieff System of movement studies. The research, therefore, revolves around the construction of foundations for a vocal work through parameters of movement. During this process, discussions related to posits of authors such as Regina Miranda, Barbara Adrian and Bonnie Bainbridge Cohen are developed. Thus, plural ways of understanding voice as movement, as spatial disturbance and as an agent of movement are emphasized. Finally, it is highlighted the importance of vocal work in widening possibilities of being in the world, recognizing the dynamics between listening and vocal production as one that underlines our self-updating processes. 


\section{Introdução: o que exploramos} quando lidamos com voz

Para grande parte de nós, falar, vocalizar, ouvir e se relacionar com pessoas oralmente é um aspecto central de nossas vidas. Ainda que existam diversos procedimentos comunicacionais - desde dispositivos técnicos às comunicações não verbais -, a voz, pela escuta e pela enunciação, é importante para como pessoas com audição se compreendem diante do mundo. Nesse sentido, as vozes fazem parte das maneiras pelas quais reconhecemos a nós mesmos e àqueles com quem nos encontramos em nossas existências, nos lembrando que cada pessoa desenvolve algo único a partir de padrões próprios de se colocar nos espaços e para os outros. É também, muitas vezes, pelas memórias de vozes que ouvimos que nós nos constituímos, seja pela sabedoria enunciada por nossos mestres ou pelas vozes proibitivas de algumas autoridades (ROSE, 2001). O "como" e o "o quê" de cada enunciação vocal, assim, nos importa.

Enquanto muitos dos estudos sobre voz a abordam a partir de explorações físicas, frequentemente a voz tem sido trabalhada como algo à parte do corpo, o que é enfatizado pelo seu caráter etéreo e pela capacidade de viajar para longe daqueles que as produzem (seja por aparelhos digitais e acústicos, seja pelo seu amplo alcance espacial). Enquanto pensar o caráter autônomo da voz é bastante importante - é central, por exemplo, para compreender como o campo da música gravada, do cinema e da televisão atuam -, é importante que a voz seja tratada também como algo que não está à parte do movimento corporal. Ela, afinal, se relaciona intimamente com os moveres dos quais ela parte. Mesmo processada, transformada e reproduzida, uma voz ainda mantém alguma relação com o corpo que a originou e, em último caso, informa as pessoas que a escutam sobre os vestígios audíveis deste outro corpo (e de como ele é imaginado pelo ouvinte).

No Sistema Laban/Bartenieff, interessado, dentre outros objetivos, em expandir as possiblidades expressivas de cada pessoa, sons e vozes povoam os escritos e práticas sobre movimento amplamente. Rudolf Laban desenvolveu um amplo trabalho teórico e prático que se preocupava com o teatro e com a sonorização e Irmgard Bartenieff (BARTENIEFF; LEWIS, 2002) propôs exercícios que se associam à vocalização e exemplificou movimento a partir de casos em que a voz aparece. Outras autoras - exploradas expansivamente neste trabalho - também abordam qualidades e transformações vocais em seus textos. Em salas de aula, nas experimentações e incorporações oriundas do sistema, falas, sons vocais, ritmos respiratórios e melodias cantadas também integram grande parte das práticas conduzidas por Analistas do Movimento pelo Sistema Laban/Bartenieff. Assim, o saber desenvolvido por estes estudos e práticas já é povoado por uma preocupação com como a voz e o movimento pelo espaço se relacionam.

Diante desse panorama e da dificuldade de encontrar trabalhos que abordem de maneira delimitada a prática integrativa de voz e movimento, este artigo se dedica, então, a mapear, elaborar e elencar postulações conceituais que circulam pelo Sistema Laban/ Bartenieff, desenvolvendo-as enquanto bases para um entendimento sobre a voz e o mover. Se muitas dessas postulações estão espalhadas entre práticas, manuais e convites para exercícios, a proposta aqui é cruzá-las para iluminar como tais desenvolvimentos podem fundamentar uma abordagem vocal por tais saberes. Portanto, este trabalho é fruto de uma revisão teórica propositiva, enfatizando o lugar do treino vocal nos escritos influenciados pela teoria labaniana. Tal revisão é feita tendo em vista um entendimento somático sobre formação de sujeito, investigando três eixos centrais: (a) os modos pelos quais a vocalização se articula com os movimentos internos, (b) a formação do espaço individual em relação à voz e (c) as relações entre cinestesia e audição. Com este percurso percorrido, se espera ser possível contribuir para o entendimento do Sistema Laban/ Bartenieff como um conjunto de conhecimentos capaz de propor práticas e teorias afinadas com perspectivas contemporâneas sobre corpo e subjetividade, sublinhando a importância de estar vindo-a-ser. 
Voz como movimento: as capacidades sensório-motoras na produção vocal

Ao apresentar a respiração como movimento fundamental para a vocalização, Barbara Adrian (2008), em seu livro dedicado à formação vocal e corporal do ator a partir do Sistema Laban/Bartenieff, sugere uma anedota parental: a respiração é apresentada metaforicamente como a mãe do movimento, da voz e da fala. Não é à toa, assim, que a autora proponha que o ponto zero para o trabalho do ator seja a exploração do suporte respiratório: é ele que permite que o movimento se desenvolva e, a partir dele, se produza a voz, por meio da qual se encaminha a fala. Nesse esquema, a fala não é um destino essencial da voz, mas está intimamente vinculada aos seus processos moventes.

$\mathrm{Na}$ apresentação de Adrian, assim, voltada principalmente para o trabalho de produção gestual e vocal, a voz se configura como o som que - projetado por uma série de movimentos internos ao corpo - se catapulta para o espaço, construindo relações com os ambientes e outros seres. Neste esquema, ela utiliza os termos voz e som "de maneira intercambiável para significar qualquer som que atravesse a boca ou a garganta" (ADRIAN, 2017, n.p., tradução nossa). Em termos de movimento, o processo de produção vocal é explicado por ela sucintamente:

O som se inicia quando a pressão do ar exalado induz oscilação das pregas vocais, o que leva o ar a vibrar enquanto passa por tais pregas. As vibrações do ar exalado acertam, então, as superfícies duras da boca e da garganta (a cavidade faríngea), criando ressonância. A ressonância vibra o ar para fora do corpo, espalhando então o som para o ambiente. (ADRIAN, 2008, n.p., tradução nossa).

É a respiração, afinal, complexamente formada pela inspiração e pela expiração, que possibilita a própria emissão de som. Tal compreensão da produção vocal enquanto uma série de movimentos, evidentemente, possibilita que diversos parâmetros de entendimento do mover sejam aplicados a todo o caminho da vocalização. Aqui, pensar variações de qualidades de movimento envolve se voltar para a voz - gerada a partir do suporte da respiração - por meio de todo seu potencial expressivo.

Laban (1978), ao propor os modos pelos quais seu sistema de entendimento de movimento contribuía para o teatro, por exemplo, pontua que a voz é "o movimento das cordas vocais" (p. 21) e lembra que os movimentos que geram a voz podem ser "ouvidos, mas não vistos” (p. 26). Regina Miranda (2008), em concordância, ao exemplificar a maneira pela qual a noção de fraseado se vincula ao tema labaniano da ação-recuperação, emprega especificamente um exemplo vocal, acrescentando a ideia de que a fala pode ser compreendida "como movimento e não como algo associado ao movimento" (p. 44). Em sua discussão, a autora nos lembra que cada pessoa tem maneiras próprias de falar e que essas maneiras podem ser entendidas por parâmetros do movimento:

Algumas usam tempos rápidos, outras usam maior número de contrastes sonoros, há quem fale entremeando muitas pausas enquanto outras falam num jorro quase ininterrupto. Conhecemos também a variedade de timbres e dos diversos lugares do corpo de onde pode provir a fala. $E$ tudo isso difere de uma pessoa para outra, tendendo a permanecer mais ou menos de forma constante em cada uma, formando o seu estilo de movimento. (MIRANDA, 2008, p. 44).

Pode-se notar, assim, que a voz - em fala, canto e demais modos expressivos - é não só fruto de uma série de movimentos (intercostais, faríngeos, orais e respiratórios de maneira ampla), mas também se faz por ondas sonoras pelo espaço interno e externo e, portanto, pode ser tomada enquanto movimento.

Partindo do corpo, é a partir de nosso maquinário sensório-motor que nos organizamos para a produção vocal. Como pontua habilmente Adrian, muitas das capacidades expressivas surgem de ações que partem de pulsões - no original chamadas de impulses - que consistem na "resposta instantânea do corpo inteiro a uma necessidade" (ADRIAN, 2008, n.p., tradução nossa). Isto é, os modos pelos quais mo- 
vimentos são produzidos também em termos vocais se articulam às necessidades que surgem em contato com o ambiente e, assim, a expressão vocal (no canto, na fala e em outros diversos sons) se dá pela interação. A voz, como movimento, então, se produz a partir de motivações que articulam o corpo - como um sistema complexo - com os espaços, ambientes e outros seres. Nesse sentido, compreender a voz tanto enquanto movimento quanto como produto de uma série de movimentos envolve refletir sobre o potencial que a produção vocal possui de criar conexões, principalmente entre as partes do corpo.

Por conta desse aspecto, Adrian recorre aos Bartenieff Fundamentals (BARTENIEFF; LEWIS, 2002) como maneira de integrar as partes do corpo e as diversas maneiras de conectá-las em função do movimento, amplamente, e da produção vocal, mais especificamente. Tais fundamentos aparecem em seu texto como um sistema que permite uma reeducação do corpo guiada de dentro para fora. A voz, assim, sendo movimento e simultaneamente produto de uma série de movimentos internos, aparece como uma maneira de compreender a própria anatomia do corpo e suas qualidades expressivas, assim como um modo de chamar a integração total do corpo para a ação. Ou seja, o desejo ou necessidade de produzir som é também um motivo para o agenciamento de diversas organizações corporais. Assim, emitir voz em diferentes qualidades - a partir das diversas necessidades e desejos - envolve assumir variadas disposições de corpo e organizações do sistema sensório-motor. A enunciação pode ser também o próprio motivo para a transformação corporal - e não só um produto de determinadas disposições físicas. Como movimento, portanto, a voz é tanto resposta quanto agente do corpo como arquitetura viva e dinâmica. O corpo, portanto, não precisa ser organizado silenciosamente para então ser capaz de produzir voz de maneira eficiente: a própria motivação para enunciar voz e escutá-la também provocam, pois, mudanças de forma, postura e padrões de conectividade.

A voz, afinal, para que seja formulada, ativa o suporte respiratório a partir das musculaturas inter- costais, do diafragma, do abdômen, mas também da faringe, laringe, boca e nariz. Nesse processo, vibra ar nas pregas vocais e ressoa, com auxílio da faringe e da cavidade oral, em diversas zonas do corpo: ao falarmos, cantarmos ou vocalizarmos livremente, estamos convidando para a ação variadas partes corporais. A produção tonal se articula, dentre outras coisas, com a variação dos lugares de ressonância que podem ser explorados no corpo. Adrian (2008) sugere que podemos pensar em variadas possibilidades de lugares por onde o som pode vibrar para se formar a voz, pontuando a importância especial da boca, do nariz e seios da face, do topo da cabeça e da caixa torácica. Então, ativando musculaturas e literalmente vibrando pelas cavidades e partes duras de nosso corpo, a voz pode ajudar a construir conexões entre partes inferiores e superiores, pode nos ajudar a mapear a espinha dorsal, a perceber as tensões espaciais que percorrem o tórax e a distinguir amplamente os lugares em que o som ressoa, colaborando no mapeamento sensível da própria anatomia. O trabalho de movimento pode, então, ser também explorado a partir da voz como uma motivação que pode gerar ações (como transferências de peso, mudanças de nível ou de suporte) que se transformam à medida que os iniciamos pelo som ou que exploramos diferentes áreas de ressonância do corpo.

Em seus textos, Peggy Hackney (2002) - interessada em pensar como o trabalho de Bartenieff atua na busca de conectar o corpo integralmente se refere recorrentemente ao processo de "repadronização" e de resgate e retorno dos padrões neurocelulares básicos de conectividade do movimento como sendo uma aventura. A autora - como Bartenieff - destrincha especificamente como a integração do corpo em suas partes e com outros corpos constrói relações e conexões que são capazes de transformar as vivências físicas e subjetivas que temos com outros e conosco. A mutabilidade, o fato de estarmos sempre em movimento, junto a um senso de inteireza (wholeness), aqui, são chaves para as construções de conexão entre parte e todo, si mesmo e outros. Mesmo um pequeno movimento que des- 
loque determinadas partes corporais demanda uma adaptação do corpo como um todo, modificando as relações que se estabelecem até então. A produção sonora, mobilizando diversos sistemas corporais a partir da necessidade e do desejo de agir, parece fazer o mesmo e, se trabalhada cuidadosamente, pode nos convidar constantemente a nos reorganizarmos.

\section{Voz como projeção do corpo: ocupando e criando espaços}

Enquanto os movimentos internos da produção vocal podem ter um papel fundamental nas diversas organizações corporais, o potencial da voz de se formar fisicamente para além dos limites do corpo é uma característica extremamente importante para a função relacional que ela estabelece em nossas vidas. Como descreve belamente Adrian (2008), dirigindo-se ao leitor:

\begin{abstract}
O som da sua voz irradia para além dos limites corporais do seu corpo. Você não pode impulsionar seu corpo, sem consequências sérias, através da parede, dos telhados ou subir instantaneamente seis lances de escada. Mas a voz pode e dá tais saltos. Ela continua a voar para o espaço, onde o corpo não pode ir. A voz pode encolher para viajar através das passagens mais estreitas ou se expandir para encher um anfiteatro de dois mil assentos. Uma vez libertada do corpo, a voz é desimpedida pelas articulações, ossos, ligamentos e músculos e, portanto, tem um potencial de flexibilidade que o corpo nunca pode alcançar. Enquanto a produção de som é uma ação muscular tanto quanto alcançar um garfo, a ressonância vocal se estende além da iniciação muscular, usando o espaço oral (boca) e arquitetônico (sala, teatro, ao ar livre) como caixas de ressonância. As vibrações resultantes produzem ondas de som que irradiam para o ambiente, como perturbações que resultam no arremesso de uma pedra em água parada ou nos traços de fogos de artifício de quatro de julho acenando à noite. (ADRIAN, 2008, n.p., tradução nossa).
\end{abstract}

Todos esses feitos que a voz pode fazer para além do corpo - como voar pelo espaço, encolher, se estreitar, transformar os ambientes - se referem, então, a uma projeção dos movimentos que a originaram no corpo físico, mas também enaltecem as diferentes qualidades que a voz pode assumir com certa autonomia ao passear pelo espaço. Esta autonomia da voz - ao se distanciar do corpo - tem sido explorada intensamente por autores da música, semiótica e dos estudos culturais. Dentre eles estão, por exemplo, o francês Roland Barthes (2012), a artista australiana Norie Neumark (2010) e o comunicólogo Thiago Soares (2014), interessados, cada um a seu modo, a investigar os efeitos da voz na escuta de outras pessoas. Tais estudos se preocupam com como a voz produz, projeta ou se distancia de determinadas qualidades corporais, pensando como a materialidade do som vocal se transforma a partir de dispositivos técnicos de captura e reprodução de som, como é transformada em diferentes contextos técnicos e culturais.

A filósofa Adriana Cavarero (2011), em sua fenomenologia da expressão vocal, desenvolve uma perspectiva que pode nos ajudar a compreender o caráter comunicacional e relacional da voz em um nível interpessoal, oriundo do potencial das vocalidades (as qualidades vocais) de se projetarem no espaço e para os outros. Em sua perspectiva, a voz, mesmo se distanciando do corpo e tendo certa autonomia, sempre nos lembra do seu caráter corpóreo: a enunciação vocal comunica, mesmo que sem formação de palavras, a vitalidade única de cada ser. Assim, ao enunciarmos vocalmente qualquer som, estamos, no mínimo, comunicando para os outros nossa presença física neste tempo e espaço, projetando nossa capacidade singular de gerar voz:

A voz é o equivalente daquilo que a pessoa única possui de mais escondido e mais verdadeiro. Não se trata, porém, de um tesouro inatingível, de uma essência inefável e, muito menos, de uma espécie de núcleo secreto do eu, mas sim de uma vitalidade profunda do ser único que goza da sua autorrevelação por meio da emissão da voz. (CAVARERO, 2011, p. 19). 
Com isso, a autora, está preocupada com como a voz, ainda que destinada à palavra e ainda que diversas pessoas falem os mesmos termos, está sempre vinculada ao reconhecimento de um corpo - que toma como carnal -, já que faz vibrar a úvula, pressiona o ar, reverbera nas cavidades da cabeça e do tronco. O ponto central de sua escrita está em compreender que cada enunciação vocal - seja ela falada, cantada, gritada ou murmurada e mesmo que emitida por uma mesma pessoa - comunica de diferentes maneiras um caráter presente e único: duas vocalizações não podem ser iguais. Isto é importante porque permite que percebamos com mais clareza que a voz - para além do canto e da fala - produz propriedades únicas em termos de movimento e que funciona de maneira a colocar em relação diversos seres, em um esquema de alteridade. Para Cavarero (2011), nós, afinal, diferenciamos vozes também pelas maneiras como percebemos que elas são diferentes ou semelhantes aos nossos próprios sons. Ao sussurrarmos, falando com calma e leveza, por exemplo, estamos comunicando - junto às palavras - um estado próprio de movimento, que expressa de alguma maneira como estamos no momento da vocalização, como nos relacionamos com o ambiente e como potencialmente nos diferenciamos de outros sons que circulam pelo espaço. Cada enunciação, assim, possui uma esfera vocálica, para além de semântica, que permite que as pessoas identifiquem ou fabulem nossos estados físicos, mas que certamente as lembra que existe um outro ser que, pela voz, anuncia sua presença.

Esse tipo de entendimento de voz como relação, colocado pela própria Adrian em suas discussões, é o que a faz se preocupar principalmente com como a voz se produz pelo corpo e, evidentemente, se intensifica ao se pensar o trabalho do ator. Laban (1978), por exemplo, se refere, pensando produção vocal, à prática da atuação como sendo um trabalho que visa a comunicação: tal comunicação só é possível porque a voz se expande para além do corpo. Adrian (2017), em concordância, em seu capítulo escrito para o livro-manual The Laban Workbook For
Actors, compreende que a voz parte do pensamento claro voltado para a função comunicativa. Assim, se torna central a compreensão de que "um pensamento articulado deve ser tratado como um gesto, que viaja em uma trajetória específica pelo espaço para afetar o ouvinte da mesma maneira que os membros externos quando gesticulam para enfatizar nosso significado" (ADRIAN, 2017, n.p. tradução nossa).

Nesses sentidos, a voz que se projeta do corpo também ajuda a constituir a exploração espacial e atua nos modos pelos quais nos relacionamos espacialmente, com outros, mas também conosco.

As relações espaciais projetadas por cada pessoa em termos de movimento formam o espaço pessoal, que é chamado de cinesfera: uma área tridimensional volátil e movente, constituída pelo espaço que ocupamos e que podemos potencialmente ocupar - nas palavras de Laban, "o espaço ao nosso alcance", deslocado conosco como uma "aura" (LABAN, 2011, p. 10, tradução nossa). Aqui, a cinesfera é formada, também, pelo alcance mais etéreo da voz. Tal espaço individual, evidentemente, pode aumentar e diminuir de acordo com como estabelecemos as relações de nossas partes e com os outros corpos espacialmente. A cinesfera é também influenciada, como não poderia deixar de ser, por fatores culturais - como aponta Ciane Fernandes (2006) ao citar as experiências de mudanças cinesféricas da bailarina lami Rebouças em Salvador e na Inglaterra, que percebeu, em suas viagens, diferenças nas maneiras como pessoas desses dois lugares lidavam com a extensão de seus movimentos. Possivelmente, essas mudanças também se materializavam nas maneiras como as pessoas empregavam o alcance de suas vozes; em como constituíam seus espaços individuais vocalmente visando a relação.

Ao se pensar voz em relação à categoria Espaço, então, é importante se atentar ao seu potencial de expandir e reformular a cinesfera: mais do que revelar o estado de quem emite a voz, as ondas sonoras se produzem também no espaço externo e se transformam por ele. Como pontua Adrian, pois, a voz passeia alargando-se, estreitando-se, dissipan- 
do-se; transformando-se. De certa maneira, assim, as vozes comunicam tanto os modos e motivações de cada pessoa que emite sons quanto a situação do espaço em que se propagam, como salas, corredores e espaços abertos, transformando-se também a partir dos dispositivos digitais e técnicos que utilizamos cotidianamente. É comum, por exemplo, que, ao testarmos a profundidade de um buraco profundo ou de uma sala ampla, façamos uma emissão vocal para ouvir o quanto de eco o espaço nos dá em retorno. Assim, conhecemos as propriedades físicas do espaço em relação ao nosso corpo - fazendo da voz um aspecto central para a exploração do espaço individual. Sucintamente, ao emitirmos voz estamos não só ouvindo nosso corpo, mas também adquirindo feedbacks sobre os ambientes em que estamos inseridos e sobre as tecnologias de captura e reprodução sonora com as quais nos relacionamos.

Nesse sentido, a voz - produzida e simultaneamente escutada - é um dos modos básicos pelos quais percebemos nossa presença física em cada espaço, de maneira que é uma parte importante das Conexões Corpo-Espaço, como sugeridas por Miranda (2008) em sua releitura do corpo Laban-Bartenieff. Em seu livro, Miranda está especialmente preocupada com como a relação entre Corpo e Espaço - e como trabalhada a partir de Bartenieff (BARTENIEFF; LEWIS, 2002) - ajuda a articular a ideia de interno e externo, de um dentro e fora do corpo, já que estamos sempre nos articulando em termos espaciais, interna e externamente. Não por acaso ela propõe as noções de Corpo Topológico e de Corpo Sem Lugar: o primeiro se refere aos "processos contínuos de metamorfose corporal", o segundo "enfatiza as intensidades espaciais em atuações no corpo"; ambos partem da necessidade de pensar "um corpo cujo suporte não poderia estar localizado dentro dele, mas sim em sua troca permanente com o fora-dentro de si" (MIRANDA, 2008, p. 33).

Nesse sentido, o trabalho de Miranda se dedica a ampliar o trabalho labaniano, mostrando como a investigação de outras geografias e matemáticas menos mensuráveis dialogam com a complexidade qualitativa do espaço para Laban. Muitas vezes, este movimento torna positivas algumas contradições que já existiam nos textos labanianos, evidenciando como o trabalho pelo sistema Laban/Bartenieff é complexo. A topologia aparece para Miranda, então, como modo de potencializar as abordagens qualitativas sobre a categoria Espaço, já que o trabaIho a partir da geometria euclidiana - pautado em linhas, ângulos e direções precisas - enfoca uma tendência fortemente quantitativa. A topologia, com figuras pautadas pela plasticidade (como o Toro e a Fita de Moebius, que se torcem em si mesmos), afinal, permite achatamentos, alargamentos e diversos tipos de transformações permanentes, atualizando-se por essas mudanças (MIRANDA, 2008).

A voz, então, sendo ao mesmo tempo produzida no corpo e no espaço, simultaneamente emitida e escutada, pode ser entendida como um fator importante na encarnação de tais discussões. Produzir sons vocais, afinal, é tanto se organizar para a emissão quanto se transformar pela escuta da própria enunciação, de maneira cíclica, realizando movimentos que simultaneamente se dirigem para fora e para dentro do corpo, topologicamente. Nesse esquema, as diferentes maneiras pelas quais nos dispomos para ouvir e produzir sons, para escutar a si e ao outro, muitas vezes assimetricamente, nos modulam em relação a como lidamos com as especificidades de cada situação e espaço.

\section{Movendo por/com vozes:} cinestesia, produção vocal e audição

Até então, a discussão aqui apresentada caminha para compreender como a voz tanto se produz por uma série de movimentos internos como também, enquanto movimentos de ondas, se transforma pelo espaço e pelos dispositivos com os quais nos relacionamos. Nesse sentido, enquanto emitimos sons e os ouvimos simultaneamente, estamos nos organizando para a produção vocal, mas também para a escuta, que nos informa sobre nossa fisicalidade e sobre como estamos nos relacionando com 
cada espaço, a partir de mudanças na Forma da voz. Durante nossas vidas, escutamos e percebemos, porém e evidentemente, outros seres e pessoas que não são nós mesmos: este é um fator central na maneira como nos produzimos em termos de movimento e, assim, influi nos modos pelos quais nos projetamos vocalmente. É importante que percebamos, portanto, mais enfaticamente como a escuta - e a percepção de maneira mais ampla - é central na maneira como movimento e voz se vinculam.

Bonnie Bainbridge Cohen (2015), em sua discussão sobre somática pelo método Body-Min$d$-Centering, produz discussões sobre a relação entre voz e cinestesia pela audição que são especialmente importantes para compreender o papel da escuta. Em tal momento de seu trabalho, ela sugere exercícios vocais que se orientam, dentre outros saberes, a partir do Sistema Laban/Bartenie$\mathrm{ff}$, propondo inclusive escalas espaciais de exploração vocal e vogal. Em seu texto Cohen está preocupada com como uma educação somática da voz pode auxiliar no desenvolvimento do movimento e na função da fala e da linguagem, apontando que

Nós vocalizamos aquilo que ouvimos, baseados em padrões neuromusculares estabelecidos em nossa respiração e movimento. Para a maior parte das pessoas, falar é uma função ou atividade automática e não percebemos conscientemente as nossas estruturas vocais. Se a integração audição/respiração/movimento/fala estiver desimpedida e desinibida, então o desenvolvimento da linguagem e a produção da fala serão eficientes e não precisaremos perceber conscientemente essas estruturas ou o seu processo (COHEN, 2015, p. 152).

Nessa perspectiva, enquanto todas as faculdades sensíveis são importantes na elaboração do movimento e da voz, Cohen reconhece que o ouvido tem um papel especialmente relevante nos nossos primeiros momentos de desenvolvimento de movimento (e de capacidade vocal), dado que mudanças nas nossas vozes funcionam de maneira a treinar nossos ouvidos e vice-versa (COHEN, 2015). Neste processo, o movimento e a função da fala se relacionam por meio da interação com a audição, de tal forma que o inter-relacionamento entre fala e audição é chamado por ela de linguagem e o "relacionamento entre movimento e audição é chamado de comunicação não-verbal" (p. 153). A audição é importante, assim, pois age ativamente - junto a outras maneiras de sentir o mundo - na produção do movimento, dado que "o movimento dos bebês se desenvolve em resposta ao som e ao ritmo da linguagem dirigida a ele", assim como a partir de respostas cinestésicas ao "movimento e ao ritmo da forma como são manuseados, às práticas culturais de sua educação, à sua imitação do movimento das pessoas ao seu redor e ao seu ambiente emocional, intelectual e espiritual" (COHEN, 2015, p. 153). Evidentemente, cada pessoa, de acordo com suas singularidades e capacidades sensíveis, desenvolve-se de diferentes maneiras, enfrentando e solucionando desafios cotidianos.

$\mathrm{O}$ argumento de Cohen se apoia na ideia de que transformações na cinestesia transformam a produção vocal e de que o contrário também é verdadeiro; as duas instâncias (cinestesia e voz) são relacionadas pela audição, que tanto nos estimula em termos de movimentos quanto de produção vocal. Esta relação é tão forte para Cohen que ela sugere, por exemplo, que iniciou seus estudos ligados especificamente à fala para que pudesse melhorar seu mover. Ela também indica, ainda pensando na função expressiva da fala, que a língua se alinha ao movimento de tal maneira que ela percebe que frequentemente "a atitude corporal (posturas e gestos) é diferente quando se fala diferentes idiomas" (COHEN, 2015, p. 153). Neste esquema, a escuta tanto aprimora quanto é aprimorada pelo crescimento das capacidades cinestésicas e vocais. Sintetizando suas ideias, a autora coloca finalmente:

A nossa expressão vocal (falar e cantar) pode melhorar ao se aprimorar a percepção auditiva e a consciência cinestésica, com treinamento da audição e do movimento, respectivamente. A nossa audição pode melhorar com o desenvolvimento de maior sensibilidade cinestésica, que 
leva a melhora da expressão vocal. Finalmente, a consciência do nosso movimento pode ser melhorada pelo treino da audição e da vocalização (COHEN, 2015, p. 176).

Nesse aspecto, apesar de essa não ser especificamente a preocupação de Cohen, é importante que notemos que os modos a partir dos quais nos desenvolvemos vocal e gestualmente a partir da escuta se relacionam às maneiras pelas quais nos fazemos enquanto sujeitos. A musicóloga especializada em voz Freya Jarman-Ivens (2011), por exemplo, aponta que nossas disposições físicas e, especialmente, vocais se constroem a partir de como lidamos com tecnologias midiáticas (que capturam e reproduzem vozes), com nossos aparatos fisiológicos e psicológicos (como técnicas vocais e compreensões sobre nosso próprio corpo) e com tecnologias de poder (como o modo pelo qual nos produzimos em termos de gênero e raça, por exemplo). Pela escuta e produção vocal, nós nos configuramos em termos identitários, nos modulamos para falar distintamente para microfones, ambientes fechados ou abertos e para exercer autoridade e sujeição. Dessa maneira, a voz é tanto fruto de procedimentos e técnicas como é em si uma técnica relacional que nos faz no mundo e nos posiciona diante dos outros. Percebo, assim, que sua argumentação é relacionável com a discussão de Cohen no sentido de que ambas estão preocupadas com as maneiras pelas quais a escuta modula os modos a partir dos quais agimos vocal e gestualmente no mundo e pelo qual nos fazemos em termos corporais. Daiane Jacobs (2017), pesquisadora preocupada com o papel do treino e dos processos de sujeição, em consonância, demonstra especificamente que a construção da voz (e de si) depende de determinadas maneiras de escutar, afetadas pela cultura. Assim, "os tipos vocais são resultados de um tipo específico de escuta, e a padronização dos tipos vocais também é resultado de uma padronização da própria escuta", de tal forma que "as vozes são reflexos das relações entre corpos e treinamentos diários, direcionados (na arte) ou espontâneos (no cotidiano)" (JACOBS, 2016, p.
372). É importante, nesse sentido, que se desenvolvam práticas pedagógicas para voz que se somem aos treinos tradicionais e que visem fomentar outras maneiras de se organizar e agir no mundo.

Com base nessa argumentação, pode-se perceber que a chamada de Cohen para uma somática da fala pode ser compreendida também pela ideia de que, ao conhecermos e experienciarmos melhor nossas estruturas (de produção vocal, escuta e movimento), nós desenvolvemos novas maneiras de ser. Em sua proposta, o treino da voz aparece não só como uma parte do processo comunicacional, mas como uma maneira de se atualizar somaticamente no mundo - o que pode ser importante para que as pessoas se repensem em termos de corpo, mas também de identidades, em como se posicionam frente os modos de se apresentar nos seus cotidianos. Compreender o trabalho somático da voz a partir de uma preocupação com investigações sobre sujeito, assim, é importante para se perceber que, ao lidar com voz e corpo, se realiza uma investigação e potencial transformação de como as pessoas se compreendem, se comportam, se fabulam e narram a si mesmas.

Essa questão é expressamente discutida por Miranda (2008) ao apresentar como tem trabalhado artisticamente a partir das Conexões Corpo-Espaço. Em seu texto, a autora aponta que tem estimulado os artistas que trabalham com ela a desenvolver uma fala corpo-verbal que visa exercitar a crença de que é "possível, desejável e enriquecedor que pessoas diferentes, de falas diferentes, com informações diferentes, convivam, criem e exercitem discursos poéticos, que possam ser sinceramente apreciados e integrados criativamente em cena ou fora dela" (MIRANDA, 2008, p. 87-88).

Isto, afirma a autora, "permite o trânsito, recria a palavra, acha o gesto capaz de provocar deslocamento e expansão" e encara a "experiência do movimento como um processo constante de auto-redefinição" (MIRANDA, 2008, p. 88). Como postula Miranda, como ilumina Cohen e como estimula para a arte Adrian, então, atualizar-se e transformar-se ao experimentar maneiras diversas de se mover, vo- 
calizar, escutar (aos outros e a si mesmo), precisa ser um imperativo, um ponto-base, em uma perspectiva somática que vise ampliar as possibilidades cinestésicas, vocais e perceptivas de cada pessoa.

\section{— Considerações finais: reunindo bases para uma prática vocal emancipatória}

É notável, em suma, que ler os desenvolvimentos da Laban Movement Analysis, dos Bartenieff Fundamentals, do Body-Mind-Centering e das Conexões Corpo-Espaço a partir de uma atenção à voz parece enfatizar a maneira como toda essa rede de saberes aborda os modos pelas quais nos posicionamos e nos relacionamos no mundo. Modular-se para a comunicação, para a função expressiva e para os feedbacks fornecidos pelos sons espaciais são fundamentos que aparecem recorrentemente quando se pensa o movimento pela voz. Se o movimento sempre é expressivo e se a relação é central para o mover humano, a vocalização sublinha o tempo todo que estamos sempre em relação e que, assim, nossos movimentos são processos que articulam nossas percepções com nossas ações, o que sofremos e o que fazemos. Por conta disso, a voz é uma das maneiras evidentes pelas quais percebemos que estamos sempre nos atualizando em termos de movimento.

Dessa maneira, se repensar vocalmente tende a fazer aparecer momentos disparadores de um processo de "desidentificação" com a voz, estranhando determinados sons que não estamos habituados a produzir e que não compõem aquilo que comumente chamamos de "minha voz". À medida que se exploram áreas de ressonância, murmúrios, sons desestruturados, as possibilidades dos articuladores, as Formas da voz, a cinesfera vocal e diferentes qualidades de Esforço, novas qualidades de corpo e voz aparecem e mais surpresas emergem. Este estranhamento parece nos lembrar e avisar que somos mais plurais do que acreditamos e que talvez tenhamos mais potenciais do que sabemos. A exploração vocal nos lembra que estamos nos atualizando, mudando ou reincidindo, e que este é um processo constante. Nos lembra que somos formados também por assimetrias de silenciamentos e tomadas de fala, e que os padrões até então dados podem ser refeitos.

Explorar a voz somaticamente incorporando os saberes desenvolvidos a partir de Laban, assim, pode fazer perceber que a descoberta de nossa anatomia, fisiologia e nossas capacidades físicas sensivelmente, estando atentos aos nossos sons e feedbacks, é um constante trabalho de reinvenção de si, de transformações expressivas. Neste sentido, o trabalho somático da voz a partir das categorias trabalhadas pelo Sistema Laban/Bartenieff, quando encarado pelas potências e transformações do mover, podem ser importantes em um processo de reformulação subjetiva das formas de ser que estão previamente dadas. Estudar voz pelo caminho do movimento, afinal, envolve estudar como construímos relações, pontes e conexões a um nível interpessoal e social, propondo outras e novas maneiras de construí-las e nos reformulando em tal processo; uma prática central para fomentar novas e mais solidárias maneiras de viver nossas existências.

\section{Referências}

ADRIAN, Barbara. Actor Training The Laban WayAn Integrated Approach to Voice, Speech, and Movement. Ebook: Allworth Press, 2008.

Moving Your Voice: Expanding Your Vocal Creative Potential Through LMA. In: CAREY, David; CAREY; Clark. (Orgs). The Laban Workbook For Actors - A Practical Training Guide With Video. Ebook: Bloomsbury, 2017.

BARTENIEFF, Irmgard; LEWIS, Dori. Body movement: coping with the environment. Nova lorque e Londres: Routledge, 2002.

BARTHES, Roland. The grain of the voice. In: STERNE, Jonathan. (Org.). The sound studies reader. London: Routledge, 2012. 
CAVARERO, Adriana. Vozes plurais - filosofia da expressão vocal. Belo Horizonte: Ed. UFMG, 2011.

COHEN, Bonnie Bainbridge. Sentir, perceber e agir - Educação Somática pelo método Body-Mind-Centering. São Paulo: Edições Sesc, 2015.

FERNANDES, Ciane. O corpo em movimento - o sistema Laban/Bartenieff na formação e pesquisa em artes cênicas. São Paulo: Annablume, 2006.

HACKNEY, Peggy. Making Connections - Total Body Integration Through Bartenieff Fundamentals. Nova lorque e Londres: Routledge, 2002.

JACOBS, Daiane. Corpo Vocal, Gênero e Performance. Rev. Bras. Estud. Presença, Porto Alegre, v. 7, n. 2, p. 359-381. 2017.

JARMAN-IVENS, Freya. Queer Voices - Technologies, vocalities, and the musical flaw. Nova lorque: Palgrave Macmillan, 2011.

LABAN, Rudolf. Domínio do Movimento. Edição organizada por Lisa Ullmann. São Paulo: Summus, 1978.

Choreutics. Annotated and edited by Lisa

Ullmann. Hampshire: Dance Books, 2011.

MIRANDA, Regina. Corpo-espaço - aspectos de uma geofilosofia do movimento. Rio de Janeiro: 7Letras, 2008.

NEUMARK, Norie. Doing Things with Voices - Performativity and Voice. In: NEUMARK, N.; GIBSON, R.; LEEUWEN, T. (Orgs.) VOICE - Vocal aesthetics in Digital arts and Media. E-book: MIT Press, 2010.

ROSE, Nikolas. Inventando nossos eus. In: SILVA, T. T. (Org.). Nunca fomos humanos. Belo Horionte: Autêntica, 2001. P. 137-204.
SOARES, Thiago. O pixel da voz. Revista Fronteiras - estudos midiáticos. Porto Alegre: Unisinos, 2014. Anais Eletrônicos. Disponível em: revistas. unisinos.br/index.php/fronteiras/article/download/ fem.2014.161.03/4001. Acesso em: 18 set. 2016.

Recebido: $14 / 06 / 2020$

Aceito: $15 / 07 / 2020$

Aprovado para publicação: 17/11/2020

Este é um artigo de acesso aberto distribuído sob os termos de uma Licença Crea- tive Commons Atribuição 4.0 Internacional. Disponível em: <http://creative commons.org/licenses/by/4.0>.

This is an open-access article distributed under the terms of the Creative Commons Attribution License 4.0 International. Available at: <http://creative commons.org/licenses/by/4.0>.

Ce texte en libre accès est placé sous licence Creative Commons Attribution 4.0 International. Disponible sur: <http://creativecommons.org/licenses/by/4.0>. 